\title{
Teachers' Training Workshop on Assessing Student Learning Outcomes as Professional Development: A Case Study
}

\author{
Khalid Iqbal $^{*}$ \\ Muhammad Idris ${ }^{* *}$ \\ Fazal ur Rahman ${ }^{* * *}$
}

\begin{abstract}
This study was conducted to analyze the role of in-service teachers training workshop conducted by PITE, based on assessing learning outcomes (SLOs) at grade $5^{\text {th }}$. In-service teachers' trainings workshops play significant role in the professional growth of educators. Aim of the study was to explore the attitudes of the primary school teachers towards workshops, to make them aware about the importance workshops for professional development and to find out teachers skills of assessing the educational activities. A sample of 66 teachers of grade $5^{\text {th }}$ was selected as respondents for the study. Observation and informal interview was conducted for data collection. Chi-Square was used for analysis of the observation sheet and for interviews, themes and patterns were developed. The study revealed that more than half of trainees have very low knowledge of assessment practices and some of them were even not interested in the workshop. The local office also showed little interest in the workshop. In the light of findings, merit based selection, proper planning for conduction of workshops, follow-up activities, local departmental interest and provision of suitable facilities i.e. man and material were recommended.
\end{abstract}

Keywords: development, workshops, assessment, teachers attitudes

\footnotetext{
* Subject Specialist, Elementary \& SE Department KP

Email: drabuhanifa.edu@gmail.com

${ }^{* *}$ Assist professor, Department of Education: AWKUM

Email: midress@awkum.edu.pk

Associate Professor, Allama Iqbal Open University, Islamabad.
} 


\section{Introduction}

Assessing student learning outcomes was a training workshop for the in-service teachers to give training to the primary schools teachers to strengthen their professional skills about the assessment practices at grade $5^{\text {th }}$. According to Popham (2006) there is intense need for the incessant and continuous in-service training of assessment that should be lined up with the classroom assessing realities. E \& SED (Elementary and Secondary Education Department) Khyber Pakhtunkhwa is aiming to introduce uniform and universal assessment system for grade 5 by 2018 . Department is institutionalizing international best practice of assessment to improve the existing assessment practice in boards and also in classroom. The PITE team has designed teachers training program on assessment to be conducted for all primary schools teachers across the province (PITE, 2016). Gronlund (2006) is of the opinion that a perfect and reliable educational assessment program needs a lucid conception of the all learning outcomes, the instructional programs, various assessing methods and techniques which tally to the instruction programs of student's performance and which is acceptable to all.

\section{Workshop Training Manual}

E \& SED (Elementary and Secondary Education Department) has introduced curriculum based examination not only in public sector but also in private sector. PITE (Provincial Institute of Teacher Education) has assigned the responsibility to develop training manual and to train teachers on students learning outcomes (SLO) based on assessment system. Five days assessment training manual is introducing SLO based assessment by using Bloom's taxonomy to categorize SLO and develop test items when assessing students leaning. It is expected that this manual will help in improving teachers understanding and knowledge about the assessment and its various types, developing test items and using textbook effectively in the classroom for assessing children learning outcomes (PITE, 2016).

\section{Purpose of the Workshop}

The aim of workshop was to assist the educators to understand SLO base teaching and assessment, moving away from rote learning to concept based learning. Expectation of the workshop participants were: 
1. Understanding about the national curriculum

2. Classification of SLOs given in the national curriculum on the bases of three levels; knowledge, understanding and application.

3. Understanding about assessment and its relationships with bloom's taxonomy.

4. Developing MCQs, CRQs and ERQs in the given subjects

5. Developing rubrics for CRQs and ERQs.

6. Recognize the importance of providing feedback to relevant stakeholders.

7. Identifying different ways to provide feedback to students (PITE, 2016).

\section{Process/ Conduction of Training Workshop}

This workshop was managed, conducted and administered by the PITE with the collaboration of Elementary and Secondary Education Department of Khyber Pakhtunkhwa. The program was consisted of five days from 9 am to $4 \mathrm{pm}$ each and every day. Trainers were trained by the PITE from all Khyber Pakhtunkhwa and deputed to various centers/stations of the province. In each station 2 experienced trainers managed the program. The outlines and content areas of the program were provided by the PITE.

\section{Rational of the Workshop}

The main theme behind the conduction of the workshop was to improve and develop a standardized and uniform assessment program for the grade $5^{\text {th }}$ level students' of public and private sector of Khyber Pakhtunkhwa. This program was devised in such a way to achieve the SLO's of the curriculum and to enhance and improve the assessment program at primary level. It was tried to make the assessment according to the bloom's taxonomy (Cognitive, Affective and Psychomotor skills) keeping SLO's of the lesson in mind (Clark, 2004).However at this stage only three levels of the cognitive domain were taken i.e. Knowledge (information), Comprehension and Application. The technical area of the workshop to bring uniformity and standardization in the assessment practices was how to develop and then to make rubrics for the assessment of:

a. MCQs (multiple choice questions)

a) CRQs (constructed response questions)

b) ERQs (extended response questions) 


\section{Literature Review}

Workshop is a mode of learning process and methodology in which an interactive process is used for learning and the participant actively engaged in the process of learning. The trainers play double role in this process; he has to play the facilitator and the instructor as well. In workshop the trainer used different types of learning techniques and approaches to facilitate the trainee, and uses his experiences to equip the trainees. He often uses role playing, demonstration, discussions, games etc for sharing the learning. He also guided the participants to work out his own actions and plans for applying some novel and innovative skills.

\section{Teachers' Professional Development}

Such different kinds of educational and learning experiences related to an individual work that enhance his abilities and skills are called professional development. Various professionals like lawyers, educators, engineers, accountants, doctors and other people take part in the professional development program to learn, enhance and apply new skills and knowledge to develop and expand their existed knowledge and improve job performance (Mizell, 2010).According to Guskey (2000) three things should be kept in mind while evaluating a professional development program. These are the concern of the teachers while they are under process of changes, involvement of teachers in applying new methods and techniques and its effects on growth and acquisition of learning and performance. It also determined if these new practices are novel in learning or not.

Experts are of the opinion that professional development is playing significant part in the growth of the instructional environment of the classroom and enhancement of the students learning and achievements (Cohen \& Hill, 2000; Corcoran, Shields,\& Zucker, 1998; Elmore, 1997; NCTAF, 1990; Darling-Hammond \& McLaughlin, 1995; Little, 1993). Skills and knowledge development of the educators enable them to tackle the challenges faced by learner and it can be best achieved by the effective professional development of the educators. A careful and sound planning, its implementation and then providing feedback are the vital parts of professional growth. After getting the professional growth the educators must apply the new knowledge and skills they have learnt. If their instructional and administrative skills did not improve it cannot be called the effective professional development (Mizell, 2010). 


\section{Assessment as a Professional Development}

Educational assessment is part and parcel to teaching profession. Assessment is the procedure of techniques through which educators get information about the performance of the students in classroom situation. In this process the teacher used various methods and technique and determined the targeted achievements and learning outcomes of the students (Gronlund, 2006).According to Koh (2011) Educational assessment is one of the potent instruments used for the improvement of educational systems. Its effectiveness is depending upon the skills, knowledge, attitudes and competence of educator and the practice due to the frequent contacts and communication between these elements or dimension (Calderhead, 1996). The standards which have been described by AFT, NCME and NEA (1990) emphasizes that teachers should be able to select and develop an assessment technique or method which is suitable:

1. To take decisive steps about teaching learning process,

2. To manage, grade and figure out the outcomes of teacher made and external assessment,

3. To utilize the result in decision making process,

4. To build up bona fide grading process,

5. To share the results of assessment to different viewers,

6. To identify the wanton, illegitimate and out of date methods and exercises of assessing practices.

The primary and basic role of assessment program is to give information that helps the educators, i.e. teachers, students, administrators and other decision and policy makers to arrive the correct decisions (Pelligrino et al, 2001). Kellough \& Kellough (1999) characterize the assessment as following:

1. To provide assistance to students learning

2. Identification of the weakness and strengths of the students

3. Evaluation of the effectiveness of teaching and instructional strategies

4. Assessment and improvement of the curriculum program

5. Assessment and improvement of teaching program

6. Providing data for decision making.

Brookhart (2011) stressed that the existed concept of formative assessment skills and knowledge is not considering by STCEAS (Standards for Teacher Competence in Educational Assessment of 
Students) and educators assessment skills needed to work effectively and successfully in the standard based assessments text. She suggests a set of techniques for educators for standard-based assessment systems.

\section{Objectives}

Objectives of the case study were:

1. To explore the attitudes of the primary school teachers toward workshops.

2. To make aware the primary school teachers about the importance of conducting workshops for professional development.

3. To find out the views of teachers about their skills of assessing the educational activities.

4. To find out the knowledge and worth of the assessment training for grade $5^{\text {th }}$ students.

\section{Methodology}

\section{Population}

The important task in the study design phase is to recognize suitable participants and the decision of selection in this regard is based upon the research question, theoretical perspectives and evidence informing the study(Sargeant, 2011).The aim of the workshop was to give SLO's (students learning outcome) based assessment training to the entire primary schools teachers of grade $5^{\text {th }}$ of Khyber Pakhtunkhwa to strengthen their assessment skills. Therefore, all primary schools teachers of Khyber Pakhtunkhwa constituted population for the study. The study was delimited the government primary schools for Boys of district Mardan as the researcher was assigned witha task to provide training in district Mardan. According to the Annual Statistics of Government Schools issued by Elementary and Secondary Education Department Khyber Pakhtunkhwa, there were total numbers of 812 functional government primary schools for boys in district Mardan. The total numbers of working teachers in these primary schools were 3498 (EMIS, 2015). E \& SED (Elementary and Secondary Education Department) Khyber Pakhtunkhwa nominated and provided list of PST (Primary School Teachers) to participate in the assessment workshop conducted under the banner of PITE. 


\section{Participants and Sampling}

In case study the researcher is charged with selection of unit of analysis. The educational researcher's unit of analysis may be a child, a classroom of children or an entire school district, depending upon the research question. In case study research mostly purposive sample is used because the investigator wants to understand and gain insight and therefore must select a sample from which the most can be learned. Screening procedure can also be used to avoid problem associated with choosing particular case or cases. Screening helps the researcher to determine the case study participants have the necessary experience and knowledge about the phenomena(Gay \& Mills, 2015). Sargeant, 2011)stated that, "The subjects sampled must be able to inform important facets and perspectives related to the phenomenon being studied. For example, in a study looking at a professionalism intervention, representative participants could be considered by role (residents and faculty), perspective (those who approve/disapprove the intervention), experience level (junior and senior residents).

In this study convenient and purposive samples (participants) of 66 teachers were selected to take part in the training workshop conducted by the provincial government for the assessing student learning outcomes to provide them assessment skills. The list of the participants (trainee teachers) was provided by E \& SED (Elementary and Secondary Education Department) Khyber Pakhtunkhwa. Ishak \& Bakar, (2014) stated that the question of random sampling for qualitative study should not arise because data collected is not meant to be generalized. Particularly, in case study, the data is meant to describe and to explain the phenomenon experience by the samples or participants of the study. There are enough participants needed to help explain the phenomenon. If a participant originally selected case study provides data that bring a new twist to the study, the researcher can command a change of new case study design and therefore a new sampling procedure.

\section{Training Procedure}

The training was conducted in two rounds at GPS No. 1 Katlang, district of Mardan, therefore the sample was divided in two groups; each of the group was consisted of 33 participants as provided by the PITE (Provincial Institute of Teacher Education). The venue of the training, manual for trainee teachers, textbooks for grade 5 and contents for the training were provided by the PITE. The topics covered during the training were assessment and its types, assessment and its cycle, bloom taxonomy required for the grade $5^{\text {th }}$ level, portfolio and test, cognitive level learning 
outcomes. They were also inculcated skills for designing different types of SLO's based questions i.e. MCQs (multiple choice questions), CRQs (constructed response questions) and ERQs (extended response questions) and making rubrics for making these types of questions.

Training/ workshop was conducted in two phases, one from $24^{\text {th }}$ of February to $28^{\text {th }}$ of February 2017 and second was from $3^{\text {rd }}$ of January to $7^{\text {th }}$ of January, 2017. Actually there were two workshops conducted each having 33 different participants. The trainers/Instructors, course contents, venue and manual for participants were remained the same in both of the phases.

\section{Research Instrumentation}

In qualitative research most common methods used are individual or group interviews including focus groups, observation and document review. These can be used alone or in combination (Sargeant, 2011). In this study participant observation and Informal interview were used for data collection. For making observation of the people, one has choice between two ways of observation i.e. participant observation and unobtrusive observation (Driscoll, 2011). In this study participant observation was used. There were two observers and the researcher was one of them. They were also the master trainers of the workshop. An observation sheet was prepared which was composed of 16 statements ( observations) and having two options "Yes" and "No" and the observer have to tick one of the option. Informal interviews were also used as instrument for data collection as in-depth information was needed for the research study. For interview Modified analytical induction approach was applied. Driscoll, (2011) is of the opinion that the best way to get in-depth information from any individual for your research project is interview or question and answer session, so interviews were also conducted to get the in-depth information. However, some of the indicators were kept in mind during the conduction of the interviews. These indicators were:

\section{Indicators for Interviews}

The following areas were focused for interviews:

1. Teachers background/ experience

2. Need of training

3. Awareness of teachers about workshop

4. Perceptions of trainee teachers about the workshop

5. Contents knowledge of the teachers. Knowledge about assessment of the teachers 
6. Previous knowledge about the program

7. Awareness of teachers about the training

8. Planning and administration of workshops

9. Lack of teaching material

10. Communication between the department officer, trainee and trainer

11. Controversies about the training

12. Trainee teachers perception about the result of the program

\section{Data Analysis}

For the analysis of the observation sheet non-parametric test i.e. chisquare was used and for the analysis of the interviews modified analytical induction approach was applied. Iterative process of data collection was applied until it was focused on the specific findings. The collected data of the interviews were codified very carefully after the codification, themes and patterns were drawn out to refine the raw data. Thus, data were refined and conclusion was drawn.

\section{Analysis and Results}

The data obtained through observation sheet was analyzed by SPSS (statistical package for social sciences) version 16 . When the calculated chi square was found greater than table value (3.841) at the significant level of 0.05 ,the statement was significant and supported and when found less than table value the statement was not accepted. The data obtained by interviews were organized, categorized and codified. Patterns and themes were developed during the interviews process. The main themes which were developed from the interviews and later on narrated in the findings and discussion were;

Table 1

Theme of the Interviews

\begin{tabular}{ll|ll}
\hline S.\# & Theme & S.\# & Theme \\
\hline 1 & Involvement of Teachers & 9 & Previous Knowledge \\
2 & Time and Space & 10 & Awareness of Trainees about Workshop \\
3 & Competency of Trainee & 11 & Planning for Workshop \\
4 & Participants' Selection & 12 & Department Involvement \\
5 & Provision of Facilities & 13 & Feelings about changes \\
6 & Contents Relevancy & 14 & Economic Incentives \\
7 & Interest of Teachers & 15 & Objectives of Workshop \\
8 & Interaction among teachers & 16 & Follow up of workshop \\
\hline
\end{tabular}


Themes were fined and refined and findings and conclusions were drawn.

\section{Analysis of the Observation Sheet}

Table 2

Analysis of the statements of the observation sheet.

\begin{tabular}{|c|c|c|c|c|c|}
\hline S\# & Observational Factors & Yes & No & $\mathrm{X}^{2}$ & $\mathrm{P}$ \\
\hline 1 & Teachers are aware about the conduction of workshop & 26 & 40 & 2.97 & .085 \\
\hline 2 & Objectives of Workshop were clear & 50 & 16 & 17.51 & $.000^{*}$ \\
\hline 3 & Contents were relevant to the workshop & 46 & 20 & 10.24 & $.001 *$ \\
\hline 4 & $\begin{array}{l}\text { Professional competency of the trainee for the } \\
\text { training }\end{array}$ & 44 & 22 & 7.33 & $.007 *$ \\
\hline 5 & Local department properly informed the trainee & 26 & 40 & 2.97 & .085 \\
\hline 6 & $\begin{array}{l}\text { Perceptions of the trainees were clear about the } \\
\text { program }\end{array}$ & 27 & 39 & 2.18 & .140 \\
\hline 7 & Trainee teachers knowledge about the content & 28 & 38 & 1.51 & .218 \\
\hline 8 & Trainee teachers interested in the training & 26 & 40 & 2.97 & .085 \\
\hline 9 & $\begin{array}{l}\text { Teachers previous knowledge about the assessment } \\
\text { process }\end{array}$ & 28 & 38 & 1.51 & .218 \\
\hline 10 & Provision of training material for workshop by PITE & 52 & 14 & 21.87 & $.000 *$ \\
\hline 11 & Trainees satisfied the facilities provided by PITE & 50 & 16 & 17.51 & $.000 *$ \\
\hline 12 & $\begin{array}{l}\text { Planning and administration of workshop by local } \\
\text { authorities }\end{array}$ & 29 & 37 & .970 & .325 \\
\hline 13 & Facilities provided by local education department & 27 & 39 & 2.18 & .140 \\
\hline 14 & $\begin{array}{l}\text { Communication among the dept officers, trainees } \\
\text { and trainers }\end{array}$ & 30 & 36 & .545 & .460 \\
\hline 15 & Physical environment was conducive for training & 46 & 20 & 10.24 & $.001 *$ \\
\hline 16 & Involvement of teachers in workshop & 45 & 21 & 8.72 & $.003 *$ \\
\hline
\end{tabular}

From the analysis of the observation and interviews it was found out that:

1. The objectives of workshop were clear. The contents were relevant to the workshop but the local department did not properly inform the trainee teachers about the objectives of the workshop.

2. The trainee teachers were not aware of the aim of the workshop and perceptions of the trainees were not clear about the program. More than $50 \%$ of the trainees' knowledge about the content was poor. They did not possess any previous knowledge about the conduction of the assessment practices.

3. Almost more than $60 \%$ of the trainee teachers were not interested in the training. They were of the opinion that they were forced to take 
part in the training/workshop. Moreover their concerns were about economic incentives.

4. Communication gap was found among the concerned officers, trainees and trainers. No one from the district or local office visited to inquire about the program implementation. Even the concern office did not provide any list of the trainee teachers nor they paid any visit to evaluate the program proceeding.

5. The trainee teachers were fully satisfied by the facilities provided by PITE for the conduction of the program. Planning and administration on part of PITE was executed well. Lapses were observed on the part of local administration.

6. At the end trainees were very happy and got fully satisfied of the proceeding and worth of the program. Almost $90 \%$ of the trainee teachers were of the opinion that it was very fruitful workshop and they sought extensive knowledge about the assessment process. They opined for conducting of such other workshops to equip the teachers in such other practical fields of education.

\section{Discussion}

Teachers' training programs are always very fruitful and play a lucrative role in the development of professionalism of teachers at any level. Workshop conducted on the assessing students learning outcome was also aimed at improving the professional knowledge of the primary schools teachers about the assessing practices at grade $5^{\text {th }}$.

As this study was aimed at surveying the attitudes of the primary school teachers toward workshops, to make aware the primary schools teachers of the worth and value of conducting workshops for the professional growth and to find out the attitudes of the teachers about the educational assessment at grade $5^{\text {th }}$. The perception of the trainee teacher's about the competencies of educational assessment practices and their knowledge about the educational assessment at grade 5 level was also critically examined. As Guskey (2000) branded that for professional development five things are very crucial i.e. participant reaction, participant learning, institutional support and participant new skills and knowledge and student learning outcomes.

The study revealed some flaws about the program/workshop conducted. At the start of the program almost $90 \%$ of the trainee teachers were unaware of the aims and objectives of the program. It was totally the fault of the local office/ department, because they should have briefed the trainee teachers about the aims and objectives of the workshop. Secondly the trainee teachers possessed very low contents, experiential and practical knowledge about the assessment practices. 
Some of the trainee teachers were very experienced yet their level of knowledge and skills about the assessing was at very low stage.

Teachers needed to possess and to expand their classroom assessment that should line up with the practices of the experts recommended assessing program. Experts expressed great apprehension and worry about the competence and skills of the teachers' about the assessing practices (McMillan \& Lawson, 2001: Zhang \& Burry-Stock, 2003).The success and failure of the program depend upon various factors. In this particular case the arrangements of the PITE were to some extent satisfactory but not up to the mark. Time and space were under the question mark. The attitudes of the trainee teachers, their interest level, local administration interest, arrangement in local centre/stations on the part of the local education department office etc were not appreciable.

Study conducted by Plake and Impara (1992) on the attitudes, skills and practices about the educational assessment revealed that educators were not fully prepared and ready for the assessment of the students learning and performance. They marked that this question needed to be further investigated. They surveyed 555 in-service teachers in USA by using a tool consists of 35 items, called "TALQ" (Teacher Assessment Knowledge Questionnaire). It was based on "Standards for Teacher Competence in the Educational Assessment" (AFT, NCME, \& NEA, 1990).For the success of any program their follow up activities play pivotal role. $85 \%$ of the trainee teachers were of the opinion that there were many such programs failed in the recent years due to not conducting their follow up. So follow up workshops of such activities that are related to the program should be conducted as refresher courses (Hadi, Dolk, \& Zonneveld, 2010).

\section{Recommendations}

Leaning workshops are always very fruitful and handy. Government should keep it up in every area of learning and education.

- The study revealed that more than $50 \%$ of the trainee knowledge about the content was very poor. They did not possess any previous knowledge about the conduction of the assessment practices. In the light of finding it is recommended that selection of trainers and trainees should be on merit based. There should be proper criteria for the selection of trainers and trainees.

- It was find out that local department did not properly inform the trainee teachers about the objectives, time and place of the workshop. The department should try to provide better information before the conducting of such workshops to enable the trainees 
mentally prepared for the workshop. Forced participation should be avoided about $40 \%$ of the trainee teachers were of the opinion that they have been sent to attend the workshop forcefully by the department. So eventually they remained uninterested.

- Time and space for the conduction of such workshops are very necessary. The time selection should be appropriate. In running session or at the time when the classes in full swing it should be avoided. Similarly there are schools where the shortage of teachers are visible and the classes suffering lots. Similarly there are schools or venues where the conduction of workshops is very hard to conduct and the whole school environment remains disturbed due the arrangements (men and material) and thus daily routine of the learning are interrupted. So such situation can be avoided by proper planning. Such activities (workshops/trainings) can be conducted in different vacations(summer and winter).

- Communication of the concerned officers, trainee and trainer was found to be nil. No one from the district or local office visited to find about the program implementation. The department should keep more interest not only in the conduction of the workshop but also should keep vigilant eyes on the proceeding, and try to remove the challenges faced to participant of the workshops. The department should try to remove all the barriers in implementation of the workshop. It should try to facilitate the participant at their level best. If the concern officers are not available at a time due to some other engagements, he should assign this responsibility to any other capable person of the department to work as a monitor.

- It is recommended that follow up activities should be conducted. For the success of any program their follow ups play pivotal role. $85 \%$ of the trainee teachers were of the opinion that there were many such programs failed due to not conducting their follow up. So follow up activities/workshop of such activities that are related to the program should be conducted as refresher courses (Hadi, Dolk, \& Zonneveld, 2010). 


\section{References}

AFT, NCME., \& NEA(1990). Standards for teacher competence in educational assessment of students: Educational Measurement: Issues and Practice, 9, 30 32. doi: 10.1111/j.1745-3992.1990.tb00391.x

Brookhart, S. M. (2011). Educational assessment knowledge and skills for teachers: Educational Measurement: Issues and Practice, 30, 312. doi: $10.1111 /$ j.1745- 3992.2010.00195.x

Calderhead, J. (1996). Teacher beliefs and knowledge. In D. C. Berliner \& R. C. Calfee (Eds.), Handbook ofeducational psychology (pp. 709725), New York: Macmillan.

Clark, D. R. (2004). Bloom's texomomy of learning domain. Available on http://www.nwlink.com /donclark/hrd/bloom.html

Cohen, D. K., \& Hill, H. C. (2000). Instructional policy and classroom performance: The mathematics reform in California. Teachers College Record, 102(2), 294-343.

Corcoran, T. B., Shields, P. M., \& Zucker, A. A. (1998). The SSIs and professional development for teachers: Menlo Park, CA: SRI International.

Darling-Hammond, L., \& McLaughlin, M. W. (1995). Policies that support professional development in an era of reform. Phi Delta Kappan, 76(8), 597-604.

Driscoll, D.L (2011). Introduction to Primary Research: Observations, Surveys, and Interviews: Writing Spaces: Readings on Writing, 2: http://writingspaces.org/essays

Elmore, R. F. (1997). Investing in teacher learning: Staff development and instructional improvement in Community School District \#2. New York City, New York, NY: National Commission on Teaching \& America's Future.

Gay, L. R., \&Mills, G. E. (2015). Educational research: Competence for analysis and application $\left(11^{\text {th }} \mathrm{ed}\right)$. Boston: Massachusetts. Pearson.

Gronlund, N. E. (2006). Assessment of student achievement $\left(8^{\text {th }} \mathrm{ed}\right.$.). Boston: Pearson.

Guskey, T. R. (2000). Evaluating Professional Development. Thousand Oaks, CA: SAGE. 
Hadi, S., Dolk, M., \& Zonneveld, E. (2010). The role of key teachers in PMRI dissemination. In R. Sembiring, K. Hoogland and M. Dolk (Eds.), A decade of PMRI in Indonesia. Bandung, Utrecht: APS.

Ishak, N. M.\& Bakar, A. Y. (2014). Developing sampling frame for case study: challenges and conditions. Journal of Education, 4 (3), 29-35.

Kellough, R.D., \& Kellough, N.G. (1999). Secondary school teaching: A guide to methods and resources; planning for competence. Upper Saddle River, New Jersey: Merrill.

Koh, K. H. (2011). Improving teachers' assessment literacy through professional development. Teaching Education, 22, 255-276. doi: /10.1080/10476210.2011.593164

Little, J. W. (1993). Teachers' professional development in a climate of educational reform. Educational Evaluation \& Policy Analysis, 15(2), 129-151.

McMillan, J. H., \& Lawson, S. R. (2001). Secondary science teachers' classroom assessment and grading practices. (ERIC Document Reproduction Service No. ED450158).

National Commission on Teaching and America's Future. (1996). What matters most: Teaching for America's future? New York, NY: Author.

Mizell., H. (2010). Why professional development matters: Learning Forward: 504 S. Locust St. Oxford, OH 45056: www.learningforward.org

Pelligrino, J.W, Chudowsky, N, \& Glaser, R. (2001). Knowing what students know: The science and design of educational assessment. Washington DC: National Academic Press.

PITE, (2016). Assessing student learning outcomes- training manual for primary schools teachers. PITE. Peshawar

Plake, B. S., \& Impara, J. C. (1992). Teacher competencies questionnaire description. Lincoln, NE: University of Nebraska.

Popham, W. J. (2006). Needed: A dose of assessment knowledge. Educational Leadership, 63, 84-85. 
Sargeant, J. (2011).Qualitative research Part I: Participants, analysis, and quality assurance. Journal of Graduate Medical Education, 3(4), 449-452.

Zhang, Z., \& Burry-Stock, J. A. (2003). Classroom assessment practices and teachers' self-perceived assessmentskills. Applied Measurement in Education, 16, 323-342. doi: 10.1207/S15324818AME1604_4

\section{Citation of this Article:}

Iqbal, K., Idris, M., \& Fazal ur Rahman. (2018). Teachers' training workshop on assessing student learing qutcomes as professional development: A case study. Pakistan Journal of Education, 35(2), 207222.

Received on: January

Revised on: May

Accepted on: July
04,2018

27, 2018

02, 2018 